\title{
Biochemical parameter and feto-maternal outcome in preeclampsia: a hospital based observational study
}

\author{
Teena Nagar, Rajendra P. Nagar*, Manisha Gupta
}

Department of Obstetrics and Gynecology, SRG Hospital and Medical College, Jhalawar, Rajasthan, India

Received: 08 September 2018

Accepted: 05 October 2018

\section{*Correspondence:}

Dr. Rajendra P. Nagar,

E-mail: drraj_teens@ymail.com

Copyright: () the author(s), publisher and licensee Medip Academy. This is an open-access article distributed under the terms of the Creative Commons Attribution Non-Commercial License, which permits unrestricted non-commercial use, distribution, and reproduction in any medium, provided the original work is properly cited.

\begin{abstract}
Background: Preeclampsia is one of the maternal diseases that cause detrimental effects on to the maternal, fetal, and neonatal health. The objective of the present study was to analyse maternal, perinatal outcome and investigation parameter in preeclampsia.

Methods: This is an observational study and total of 90 consecutive patients were enrolled who has blood pressure $\geq$ 140/90 $\mathrm{mmHg}$ after 20 weeks of gestation with proteinuria (1+ by dipstick).

Results: Among enrolled patients, 52 (58\%) were in age group of 25-35 year and $51(57 \%)$ were primigravida. Mean systolic and diastolic blood pressure of patients was $148 \pm 3.8 \mathrm{~mm}$ of $\mathrm{Hg}$ and $95 \pm 1.4 \mathrm{~mm}$ of $\mathrm{Hg}$ respectively. Most common presenting symptom was labor pain in 65 (72\%) patients followed by edema in 61 (68\%) patients. Most common complication was CNS symptom including seizure (Eclampsia) in 13 (15\%) patients followed by vaginal bleeding (including abruption) in $12(13 \%)$ patients. Mean hemoglobin level was $9.12 \pm 0.9 \mathrm{gm} / \mathrm{dl}$. Mean urea and creatinine values were $34 \pm 4.6 \mathrm{mg} / \mathrm{dl}$ and $1.5 \pm 1.1 \mathrm{mg} / \mathrm{dl}$ respectively. Out of total 90 patients, $18(20 \%)$ had elevated liver enzymes. Most common neonatal outcome was low birth weight $63(70 \%)$ and $40(44 \%)$ were preterm. APGAR score was less than 7 in $11(12 \%)$ patients and more than 7 in $79(88 \%)$ patients. Five $(5.5 \%)$ newborn were still born. Conclusions: Preeclampsia is associated with multiple maternal and neonatal complications. Hence, there is a need for regular antenatal checkup to detect early and strengthening of neonatal intensive care units.
\end{abstract}

Keywords: Investigation, Neonatal, Preeclampsia, Seizure

\section{INTRODUCTION}

Pregnancy is a physiological phenomenon for most women. However, some develop problems during its evolution, putting both the mothers and the conceptus health at sake. Hypertensive disorders of pregnancy (HDPs) are one of the maternal diseases that cause detrimental effects on to the maternal, fetal, and neonatal health. The hypertensive disorders of pregnancy (HDPs) complicate about $3-10 \%$ of pregnancies. ${ }^{1}$ They are one of the major contributors to maternal and fetal mortality and morbidity globally; maternal complications include eclampsia, stroke, and damage to the hepatic and renal organs etc. ${ }^{2}$ Hypertension diseases during pregnancy includes pregnancy-induced hypertension (PIH) (without proteinúria), pre-eclampsia (with proteinuria), and eclampsia (pre-eclampsia with convulsions). Pregnancy termination reverses the clinical manifestations of the disease, suggesting that trophoblastic invasion has a central role in the pathogenesis of preeclampsia. ${ }^{3} \mathrm{~A}$ recent study revealed that excessive placental secretion of soluble fms-like tyrosine kinase-1 may contribute to endothelial dysfunction, hypertension, and proteinuria in preeclampsia. ${ }^{3}$ In a multicenter study, approximately $30 \%$ of HDP cases were due to chronic hypertension, while $70 \%$ were due to gestational hypertension/preeclampsia. ${ }^{4}$ 
For the conceptus, the most common consequences associated with hypertension diseases are the restriction of intra-uterine growth, low birth weight, prematurity and intrauterine death. ${ }^{5,6}$ Predicting the onset of these complications could aid in timely interventions such as increased surveillance, treatment of symptoms, transfer to higher care facility and delivery when necessary, which could reduce morbidity and mortality from the HDPs. ${ }^{7}$

Maternal risk factors used as criteria for severity classification by some international clinical practice guidelines do not accurately identify women at high risk of developing maternal complications. ${ }^{8}$ While many studies have reported associations between certain biomarkers and adverse outcomes, only a few studies have examined the accuracy of these tests in predicting adverse maternal outcomes; in other words, the accuracy of discriminating women who do experience serious morbidities versus those who do not at the individual level. ${ }^{9}$ The tests reported in these studies range from single markers to multiple markers combined in prediction models. Prediction models are increasingly used in clinical practice since they have the advantage of combining various factors to potentially provide more accurate predictions. ${ }^{10}$ Several systematic reviews have assessed the predictive ability of individual variables such as uric acid, maternal symptoms, and liver function tests for maternal and fetal complications resulting specifically from pre-eclampsia. ${ }^{11-12}$ This broader disease definition is important, as other HDPs still contribute substantially to the burden of the disease. ${ }^{4}$

Thus, the present study is an attempt to analyse maternal and perinatal outcome in preeclampsia and to find the usefulness of the clinical and investigative work up as predictors of outcome.

\section{METHODS}

This was an observational study conducted in department of Obstetrics and Gynecology at Zanana hospital, medical college Jhalawar.

\section{Inclusion criteria}

- $\quad$ Pregnant women who had blood pressure $\geq 140 / 90$ $\mathrm{mmHg}$ after 20 week of gestation with proteinuria (1+ by dipstick).

Blood pressure more than 140/90 $\mathrm{mm}$ of hg after 20 weeks of pregnancy defined as gestational hypertension. Preeclampsia is a gestational hypertensive with proteinuria (>300mg/24hour). ${ }^{13}$ When convulsions occur in addition to these signs, of preeclampsia the condition is referred to as eclampsia. ${ }^{14}$

An informed consent was obtained from the subject's prior to participation in this study. Women with preeclampsia hypertensive disorder of pregnancy were evaluated and managed as per the hospital protocol.
Blood pressure of study subjects was measured by using mercury sphygmomanometer with appropriate cuff size tied at heart level. The women were evaluated clinically as well as by investigative work up. Proteinuria was estimated daily by dip stick method. Complete blood count with platelets and Serum analysis of uric acid, creatinine, and renal and liver function tests were done by using automated analyser.

Platelet count and protein estimates in urine were done at admission and as indicated by the clinical disease behavior. A peripheral smear was done for screening for HELLP syndrome. Sonographic estimation of fetal growth, weight and amount of liquor was carried out. Women were put on antihypertensive drugs and dose adjusted or treatment with additional drugs was done as per individual requirement. Four doses of intramuscular dexamethasone $6 \mathrm{mg}, 12$ hours apart was given for preterm (less than 4 week) salvageable pregnancies. Women on expectant management were asked to report if they have headache or epigastric pain or vomiting or visual disturbances, those with eclampsia was managed by standard protocol.

Pregnancy was terminated for Eclampsia, uncontrolled hypertension in spite of being on maximum dose of antihypertensive, persisting/progressively deteriorating clinical symptoms or the biochemical markers, occurrence of complications such as placental abruption, eclampsia, renal failure and indication of non-reassuring fetal status. The decision regarding the mode of delivery was based on estimated fetal weight, salvage ability, gestational age, amniotic fluid index, fetal status and Bishop score. The neonates were managed by pedatric team at neonatal intensive care unit if needed. All the subjects were monitored, and the investigative parameters were compared with various maternal and fetal outcome.

The maternal outcomes were further divided into normal outcome, Eclampsia and other complications (Abruption, HELLP, renal failure, pulmonary oedema etc). Perinatal outcome measures that will be studied include live births, fetal growth restriction (IGUR), still births, neonatal complications (sepsis, intraventricular hemorrhage, hyperbilirubinemia, necrotizing enterocolitis) and neonatal death.

\section{Statistical analysis}

Continuous variables were presented as Mean \pm SD or Median and interquartile range. The categorical variables were presented as percentages/proportions.

\section{RESULTS}

Present study was observational study and carried out in Department of Obstetrics and Gynecology, Medical College, Jhalawar. A total of 90 consecutive patients of preeclampsia were enrolled for the study. 
Out of 90 pregnant patients, maximum $52(58 \%)$ were in age group of 25-35 year followed by less than 25 year of age $27(30 \%)$. Among enrolled patients, 51 (57\%) were primigravida and $39(43 \%)$ were multigravida.

Mean systolic blood pressure of preeclampsia patients was $148 \pm 3.8 \mathrm{~mm}$ of $\mathrm{Hg}$ and mean diastolic blood pressure was $95 \pm 1.4 \mathrm{~mm}$ of $\mathrm{Hg}$. Out of 90 patients, 55 $(61 \%)$ were delivered vaginaly and $35(39 \%)$ patients by cesarean section. (Table 1).

Table 1: Demographic profile and patient's characteristic.

\begin{tabular}{|ll|}
\hline Patients characteristic & $\mathrm{n}(\%)$ \\
\hline Age & \\
\hline$<25$ year & $27(30 \%)$ \\
\hline $25-35$ year & $2(58 \%)$ \\
\hline$>35$ year & $11(12 \%)$ \\
\hline Gravid & $51(57 \%)$ \\
\hline Primigravida & $39(43 \%)$ \\
\hline Multigravida & $148 \pm 3.8$ \\
\hline Blood pressure (BP) mmHg & $95 \pm 1.4$ \\
\hline Mean systolic BP & \\
\hline Mean diastolic BP & $35(39 \%)$ \\
\hline Mode of delivery & $55(61 \%)$ \\
\hline Cesarean section & \\
\hline Vaginal & \\
\hline
\end{tabular}

Most common presenting symptom was labor pain in 65 $(72 \%)$ patients followed by edema in 61 (68\%) and headache in $39(42 \%)$ patients. Seizure and visual symptoms were present in $9(10 \%)$ and $4(5 \%)$ patients respectively. vaginal bleeding was present in $8(9 \%)$ and jaundice in $3(3.3 \%)$ patients (Table 2 ).

Table 2: Symptomatology of patients.

\begin{tabular}{|ll|}
\hline Symptoms & N $(\%)$ \\
\hline Labor pain & $65(72 \%)$ \\
\hline Edema & $61(68 \%)$ \\
\hline Headache & $39(42 \%)$ \\
\hline Seizure & $9(10 \%)$ \\
\hline Vaginal bleeding & $8(9 \%)$ \\
\hline Visual symptom & $4(5 \%)$ \\
\hline Jaundice & $3(3.3 \%)$ \\
\hline
\end{tabular}

Most common complication was CNS symptom including seizure (Eclampsia) in 13 (15\%) patients followed by vaginal bleeding (including abruption) in 12 $(13 \%)$ and renal derangement in $4(4.4 \%)$ patients.

Other complications were pulmonary edema in $5(5.5 \%)$ and HELLP syndrome in $2(2.2 \%)$ patients.

Out of 90 patients, 4 patients died (three patients had pulmonary edema and one patient of postpartum hemorrhage with eclampsia) (Table 3). Among 90 patients, $60(67 \%)$ patients were anemic at the time of admission with mean hemoglobin level of $9.12 \pm 0.9$ $\mathrm{gm} / \mathrm{dl}$. Mean urea and creatinine values were $34 \pm 4.6$ $\mathrm{mg} / \mathrm{dl}$ and $1.5 \pm 1.1 \mathrm{mg} / \mathrm{dl}$ respectively.

Table 3: Maternal and neonatal outcome.

\begin{tabular}{|ll|}
\hline Maternal Outcome & N $(\%)$ \\
\hline CNS symptoms including seizure & $13(15 \%)$ \\
\hline Eclampsia & $9(10 \%)$ \\
\hline Bleeding & $8(9 \%)$ \\
\hline Pulmonary edema & $5(5.5 \%)$ \\
\hline Abruption & $4(4.4 \%)$ \\
\hline Renal failure & $4(4.5 \%)$ \\
\hline Maternal mortality & $4(4.4 \%)$ \\
\hline HELLP & $2(2.2 \%)$ \\
\hline Neonatal outcome & \\
\hline LBW & $63(70 \%)$ \\
\hline Preterm & $40(44 \%)$ \\
\hline Still birth & $5(5.5 \%)$ \\
\hline APGAR $<7$ & $11(12 \%)$ \\
\hline APGAR $>7$ & $79(88 \%)$ \\
\hline NICU admission & $18(20 \%)$ \\
\hline Neonatal death & $4(4.4 \%)$ \\
\hline
\end{tabular}

Renal failure was present in $4(4.4 \%)$ patients and all these patients had dearranged urea and creatinine value along with oligurea. Out of total 90 patients, 18 (20\%) had elevated liver enzymes with mean value of ALT and AST was $59 \pm 34$ IU/L and $54 \pm 13$ IU/L respectively. Visible jaundice was present in $3(3.3 \%)$ patients (Table 4).

Table 4: Investigation parameters of study patients.

\begin{tabular}{|ll|}
\hline Parameter & Value \\
\hline Hemoglobin & $9.12 \pm 0.9 \mathrm{gm} / \mathrm{dl}$ \\
\hline Platelets & $1.87 \pm 0.65 \mathrm{lac} / \mathrm{cc}$ \\
\hline Urea & $34 \pm 4.6 \mathrm{mg} / \mathrm{dl}$ \\
\hline Creatinine & $1.8 \pm 1.1 \mathrm{mg} / \mathrm{dl}$ \\
\hline Bilirubin & $1.9 \pm 1.6 \mathrm{mg} / \mathrm{dl}$ \\
\hline ALT (alanine transferase) & $59 \pm 34 \mathrm{IU} / \mathrm{L}$ \\
\hline AST (aspartate transferase) & $54 \pm 13 \mathrm{IU} / \mathrm{L}$ \\
\hline
\end{tabular}

Most common neonatal outcome was low birth weight 63 (70\%). Among all delivered newborn, 40 (44\%) were preterm. APGAR score was less than 7 in $10(12 \%)$ patients and more than 7 in $79(88 \%)$ patients. Neonatal intensive care admission was required for 18 (20\%) neonate and out of them $4(4.4 \%)$ were expired. Five $(5.5 \%)$ newborn were still born (Table 3$)$.

\section{DISCUSSION}

The maternal and perinatal morbidity and mortality due to pregnancy induced hypertension has decreased over the decade because of better antenatal care and early hospitalization. However, preeclampsia-eclampsia still stands as one of the major complications in pregnancy. The present study was done to find out the associated 
complications and laboratory parameters in patients with pregnancy induced hypertension.

A total of 90 consecutive patients of preeclampsia were enrolled for the study.

In present study, out of 90 pregnant patients, $58 \%$ were in age group of 25-35 year and 57\% patients were primigravida. Solange et al and Patel et al also reported most common age group was 20-34 year (64\%) and 18 26 year $(56 \%)$ respectively. ${ }^{15,16}$

In present study, mean systolic blood pressure of pregnancy induced hypertensive patients was $148+3.8$ $\mathrm{mmHg}$ and mean diastolic blood pressure was $95+1.4$ mmHg. Similarly, Sachan et al in their study reported mean systolic blood pressure of $145.32 \pm 9.7 \mathrm{mmHg}$ and mean diastolic pressure of $93.72 \pm 5.2 \mathrm{mmHg} .{ }^{17}$ Jun Zhang et al found that a rise in systolic pressure over $30 \mathrm{mmHg}$ or diastolic pressure over $15 \mathrm{mmHg}$ was associated with a statistically significant complicated pregnancy. ${ }^{18}$

Likewise, Pallavi et al done a study of 48 women who developed pregnancy induced hypertension and reported mean systolic and diastolic blood pressure in 3rd trimester was $146.00 \pm 2.70 \mathrm{mmHg}$ and $94.83 \pm 3.13 \mathrm{mmHg}$ respectively. ${ }^{19}$

In present study, most common presenting symptom was labor pain $72 \%$ followed by edema $68 \%$ and headache in $42 \%$ patients. Seizure and visual symptoms were present in $10 \%$ and $5 \%$ patients respectively. Vaginal bleeding was present in $9 \%$ patients. Likewise, in study done by Sachan et al reported edema as a most common manifestation followed by central nervous system involvement $(42.2 \%)$ and vaginal bleeding $(11.3 \%){ }^{17}$ Similarly Parmar et al studied 110 women and found that edema was present in $59 \%$ patients followed by headache $(33 \%)$ and visual disturbance in $19 \%$ patients. ${ }^{20}$ However, Patel et al found pain abdomen in $48.44 \%$ patients, vomiting in $18.75 \%$ and headache in $12.5 \%$ of the women with pregnancy induced hypertension. ${ }^{16}$

In present study, most common complication was CNS symptom including seizure (Eclampsia) in $15 \%$ patients followed by vaginal bleeding (including abruption) in $13 \%$ and renal derangement in $4.4 \%$ patients. Other less common complications were pulmonary edema in $5.5 \%$ and HELLP syndrome in $2.2 \%$ patients. Sachan et al also reported maternal complication in their study and found that $3.13 \%$ patient had acute renal failure and abrution was reported in $15 \%$ cases of preeclampsia. ${ }^{17}$ Most maternal complications were found in the severe preeclampsia group. The overall maternal mortality rate was $2.8 \%$. Liu et al in their study found that women with gestational hypertension and proteinuria had an increased risk of placental abruption (unadjusted OR, 4.36; 95\% CI, 1.05-18.1) and disseminated intravascular coagulation (unadjusted OR, 6.46; 95\% CI, 1.05-39.8), he also reported that maternal complications $(\mathrm{OR}, 2.59 ; 95 \% \mathrm{CI}$,
1.34-5.04) became the single significant factor associated with gestational hypertension and proteinuria. ${ }^{21}$ Nanali et al studied 349 severely preeclampsia cases and reported eclamptic seizure $(6.3 \%)$, HELLP syndrome $(0.3 \%)$ and placental abruption in $7.7 \%$ cases. The most frequent maternal complication (37 cases) reported was coagulopathy $(10.6 \%) .^{22}$

In present study mean hemoglobin level were 9.12+0.9 $\mathrm{gm} / \mathrm{dl}$ and Mean urea and creatinine values were 34+4.6 $\mathrm{mg} / \mathrm{dl}$ and $1.5+1.1 \mathrm{mg} / \mathrm{dl}$ respectively. Mean value of ALT and AST was 59+34 IU/Land 54 \pm 13 IU/L respectively. Monteiro et al in their study found that mean hemoglobin, urea and creatinine was $8.54 \pm 3.06 \mathrm{gm} / \mathrm{dl}, 27.5 \pm 16.26$ $\mathrm{mg} / \mathrm{dl}$ and $0.67 \pm 0.18 \mathrm{mg} / \mathrm{dl}$ respectively. ${ }^{23}$

Xue-Jun et al24 also found that uric acid $>7 \mathrm{mg} / \mathrm{dl}$ $(\mathrm{p}=0.001)$, platelet count $<1,00,000$ cells $/ \mathrm{cc} \quad(\mathrm{p}=0.003)$ and serum creatinine $>1.2 \mathrm{mg} / \mathrm{dl} \quad(\mathrm{p}=0.025)$ were significantly associated with poor maternal outcome in women with severe preeclampsia. Likewise, Sachan et al in their study reported mean hemoglobin, mean urea and mean creatinine $9.71 \pm 1.2 \mathrm{gm} / \mathrm{dl}, 30.05 \pm 9.7 \mathrm{mg} / \mathrm{dl}$ and $1.27 \pm 0.5 \mathrm{mg} / \mathrm{dl}$ respectively in preeclamptic patient. Mean ALT and AST in severe preeclamptic patients was $215.94 \pm 125.8 \mathrm{IU} / \mathrm{L}$ and $208.57 \pm 130.9 \mathrm{IU} / \mathrm{L}$ respectively. ${ }^{17}$

In present study, most common neonatal outcome was low birth weight $(70 \%)$ and $44 \%$ were preterm. APGAR score was less than 7 in $12 \%$ patients. Out of all delivered baby $5.5 \%$ were still born and $4.4 \%$ expired during their NICU stay. Xue-Jun et al studied 140 women among them 114 had perinatal complications. Still birth was seen in 33, neonatal morbidity was observed in 81 newborns. Perinatal complications were preterm, still birth and severe IUGR. ${ }^{24}$ There was one neonatal death due to severe respiratory distress syndrome. Parmar et al in their study observed perinatal complications in $46 \%$ cases which include IUGR (60.9\%), birth asphyxia (8.7\%), RDS $(4.3 \%)$ and perinatal death $(15.2 \%)$ respectively. ${ }^{20}$

Patel et al also reported that out of $64 \mathrm{PIH}$ mother $54.69 \%$ had preterm delivery, $4.69 \%$ had post term delivery. ${ }^{16} 53.12 \%$ of babies are low birth weight, $07.81 \%$ are IUGR. Out of 64 delivery 12 (18.75\%) of babies were required NICU admission for various causes. $1.56 \%$ were IUFD and $1.56 \%$ of neonatal death. Pairu et al in their study reported that fetal outcome, pre-term deliveries, fetal growth retardation (IUGR) and still birth was significantly more frequent in women with preeclampsia as compared to those without pregnancy induced hypertension. ${ }^{25}$

Limitation of present study was that it was observational study without control subject. We also not classified patients in different categories. Admission data and investigations were analysed although serial measurement of different parameter would be more informative. We also did not attempt to find the 
association between of individual parameter with the perinatal and maternal outcome. Being a common problem in pregnant patients, more sample size is required for better results.

\section{CONCLUSION}

Preeclampsia is associated with multiple maternal and neonatal complications. Hence, there is a need to strengthening and upgradration of neonatal intensive care units and also too aware the patients about importance of timely antenatal checkup and health education so that complication can be prevented by early intervention.

\section{Funding: No funding sources}

Conflict of interest: None declared

Ethical approval: The study was approved by the Institutional Ethics Committee

\section{REFERENCES}

1. Magee LA, Pels A, Helewa M, Rey E, von Dadelszen P, Audibert F et al. The hypertensive disorders of pregnancy (29.3). Best practice and research Clinic Obstet Gynaecol. 2015;29(5):643-57.

2. von Dadelszen P, Magee LA. Pre-eclampsia: an update. Current hypertension reports. 2014;16(8):454.

3. Maynard SE, Min JY, Merchan J, Lim KH, Li J, Mondal S, et al. Excess placental soluble fms-like tyrosine kinase 1 (sFlt1) may contribute to endothelial dysfunction, hypertension, and proteinuria in preeclampsia. $\mathbf{J}$ Clinical Invest. 2003;111(5):649-58.

4. Matthys LA, Coppage KH, Lambers DS, Barton JR, Sibai BM. Delayed postpartum preeclampsia: an experience of 151 cases. Am J Obstet Gynecol. 2004; 190(5):1464-6.

5. Brown MA, Hague WM, Higgins J, Lowe S, McCowan L, Oats J et al. Austalasian Society of the Study of Hypertension in Pregnancy. The detection, investigation and management of hypertension in pregnancy: full consensus statement. Aust NZJ Obstet Gynaecol. 2000;40(2):139-55.

6. Cunningham FG, MacDonald PC, Gant NF, Leveno KJ, Gilstrap LC, Hankins GD, et al. Williams obstetrícia. $20^{\mathrm{a}}$ ed. Rio de Janeiro: Guanabara Koogan. 2000:607-52.

7. Payne BA, Hutcheon JA, Ansermino JM, Hall DR, Bhutta ZA, Bhutta SZ, et al. A risk prediction model for the assessment and triage of women with hypertensive disorders of pregnancy in lowresourced settings: the miniPIERS (pre-eclampsia integrated estimate of RiSk) multi-country prospective cohort study, PLoS Med.2014;11(1):e1001589.

8. Menzies J, Magee LA, Macnab YC, Ansermino JM, Li J, Douglas MJ. Current CHS and NHBPEP criteria for severe preeclampsia do not uniformly predict adverse maternal or perinatal outcomes, Hypertens Preg. 2007;26(4):447-62.
9. Bramham K, Poli-de-Figueiredo CE, Seed PT, Briley AL, Poston L, Shennan AH et al. Association of proteinuria threshold in pre-eclampsia with maternal and perinatal outcomes: a nested case control cohort of highrisk women. PloS one. 2013;8(10):e76083.

10. T. Neeman. Clinical prediction models: A practical approach to development, validation, and updating by ewout W. steyerberg, Int Stat Review. 2009;77(2):320-1.

11. Thangaratinam S, Coomarasamy A, O'Mahony F, Sharp S, Zamora J, Khan KS, Ismail KM. Estimation of proteinuria as a predictor of complications of preeclampsia: a systematic review. BMC Med. 2009;7(1): 10 .

12. Thangaratinam $S$, Koopmans $C M$, Iyengar $S$, Zamora J, Ismail KM, Mol BW. Accuracy of liver function tests for predicting adverse maternal and fetal outcomes in women with preeclampsia: a systematic review, Acta Obstet Gynecol Scand. 2011;90(6):574-85.

13. Program NHBPE. Report of the national high blood pressure education program working group on high blood pressure in pregnancy. Am J Obstet Gynecol. 2000;183(1):1-22

14. Reingardiene D. Preeclampsia and eclampsia. Medicina (Kaunas). 2003;39:1244-52.

15. Solange Chaim, Sonia Oliveira, Améli Kimura. Pregnancy-induced hypertension and the neonatal outcome. Acta Paul Enferm. 2008;21(1):53-8.

16. Patel R, Baria H, Patel HR, Nayak S. A study on pregnancy induced hypertension and foetal outcome among patient with PIH at tertiary care hospital, Valsad. Int J Community Med Public Health 2017; 4(11):4277-81.

17. Rekha Sachan, Munna Patel, Pushpalata Sachan, Amrita Gaurav, Meenakshi Singh, Bhumika Bansal. Outcomes in hypertensive disorders of pregnancy in the North Indian population. Int $\mathbf{J}$ Womens Health. 2013;5:101-8.

18. Jun Zhang, Jose Villar, Wenyu Sun, Mario Merialdi, Hany Abdel-Aleem, Matthews Mathai et al. Blood pressure dynamics during pregnancy and spontaneous preterm birth. Am J Obstet Gynecol. 2007;197(2):162.11-6.

19. Kumari P, Sharma SN, Kumar S, Kumar MA. "A Comparative Study of Blood Pressure in Normal and Pregnancy Induced Hypertensive Cases for Early Diagnosis of Hypertensive Disorders in A Tertiary Care Hospital". Int J Sci Stud. 2014;2(3):33-37.

20. Parmar MR, Vaja P. Effect of pregnancy induced hypertension on maternal and perinatal outcome at tertiary care center in Ahmedabad, Gujarat, India. Int J Reprod Contracept Obstet Gynecol. 2017; 6(10):4661-5.

21. Liu CM, Cheng PJ, Chang SD. Maternal complications and perinatal outcomes associated with gestational hypertension and severe preeclampsia in Taiwanese women. J Formos Med Assoc. 2008;107(2):129-38. 
22. Nankali. A, Khosravi M, Zangeneh M, Rezaei M, Hemat Z, Kohzadi M. Maternal Complications Associated with Severe Preeclampsia. J Obstet Gynaecol India. 2013;63(2),112-5.

23. Monteiro G, Subbalakshmi NK, Pai SR. Relevance of measurement of hematological parameters in subjects with pregnancy induced hypertension. Nitte Univers J Health Sci. 2014;4(1):15.

24. Gao XJ, Ye CH, Zhao HR, Chen C. Preeclampsia related investigative parameters and its association with maternal outcome. Biomed Res. 2017;28(7):2935-40.
25. Pairu J, Bharathi KN, George K. Maternal and perinatal outcome in pregnancy induced hypertension and preeclampsia. Int $\mathbf{J}$ Reprod Contracept Obstet Gynecol. 2016;5(7):2166-70.

Cite this article as: Nagar T, Nagar RP, Gupta M. Biochemical parameter and feto-maternal outcome in preeclampsia: a hospital based observational study. Int J Reprod Contracept Obstet Gynecol 2018;7:4668-73. 